\title{
Fixed Points of G-Type Quasi-Contractions on Graphs
}

\author{
R. H. Haghi, ${ }^{1}$ Sh. Rezapour, ${ }^{2}$ and N. Shahzad ${ }^{3}$ \\ ${ }^{1}$ Department of Mathematics, Payame Noor University, P.O. Box 19395-3697, Tehran, Iran \\ ${ }^{2}$ Department of Mathematics, Azarbaijan Shahid Madani University, Azarshahr, Tabriz, Iran \\ ${ }^{3}$ Department of Mathematics, King Abdulaziz University, P.O. Box 80203, Jeddah 21859, Saudi Arabia
}

Correspondence should be addressed to N. Shahzad; nshahzad@kau.edu.sa

Received 3 August 2013; Accepted 2 October 2013

Academic Editor: S. Romaguera

Copyright (c) 2013 R. H. Haghi et al. This is an open access article distributed under the Creative Commons Attribution License, which permits unrestricted use, distribution, and reproduction in any medium, provided the original work is properly cited.

Recently, fixed point theory on graphs has been considered by many authors. In this paper, by combining some ideas in some published papers and introducing $G$-type quasi-contractions, we give some fixed point results for $G$-type quasi-contractions on graphs. The results improve some old results in the literature.

\section{Introduction}

In 2009, Ilić and Rakočević proved that quasi-contraction maps on normal cone metric spaces have a unique fixed point [1]. Then, Kadelburg et al. generalized their results by considering an additional assumption [2]. Also, they proved that quasi-contraction maps on cone metric spaces have the property $(P)$ whenever $\lambda \in(0,1 / 2)$. Later, the authors proved same results without the additional assumption and for $\lambda \epsilon$ $(0,1)$ by providing a new technical proof [3]. Also, there are some works on quasi-contractive multifunctions (see, e.g., $[4,5])$.

In 2008, Suzuki introduced a new type of mappings and a generalization of the Banach contraction principle [6]. Later, his method extended for mappings and multifunctions (see, e.g., [7] and the references therein and [8]). On the other hand, Echenique gave a short constructive proof for Tarski's fixed point theorem in 2005 by using graphs [9]. In 2006, Espínola and Kirk started combining fixed point theory and graph theory [10]. In 2008, Jachymski provided some fixed point results for Banach contractions on a graph [11]. Recently, fixed point theory on graphs has been considered by many authors (see, e.g., [12-16]).

Let $(X, d)$ be a metric space, $\Delta=\{(x, x): x \in X\}, G$ a directed graph $G$ such that $V(G)=X$, and the set $E(G)$ of its edges contains all loops. We denote the conversion of a graph $G$ by $G^{-1}$; that is, the graph obtained from $G$ by reversing the direction of the edges. Moreover, $\widetilde{G}$ denotes the undirected graph obtained from $G$ by ignoring the direction of the edges. In this paper, we consider undirected graphs. We say that a self-map $T$ on $X$ preserves the edges of $G$ whenever $(x, y) \in E(G)$ which implies that $(T x, T y) \in E$ for all $x, y \in X$. A finite path of length $n$ in $G$ from $x$ to $y$ is a sequence $\left\{x_{i}\right\}_{i=0}^{n}$ of distinct vertices such that $x_{0}=x, x_{n}=y$, and $\left(x_{i}, x_{i+1}\right) \in E(G)$ for $i=0,1, \ldots, n-1$ (see, e.g., [12]). A graph $G$ is connected if there is a path between any two vertices. $G$ is weakly connected if $\widetilde{G}$ is connected. We denote by $[x]_{G}$ the set of all vertices in $G$ that there is a path between $x$ and those.

In 2008, Jachymski used the notion of $C$-graphs for obtaining the main results of [11]. We say that $G$ is a $C$-graph whenever for each sequence $\left\{x_{n}\right\}_{n \geq 0}$ in $X$ with $x_{n} \rightarrow x$ and $\left(x_{n}, x_{n+1}\right) \in E(G)$ for all $n \geq 0$, there is a subsequence $\left\{x_{n_{k}}\right\}_{k \geq 0}$ such that $\left(x_{n_{k}}, x\right) \in E(G)$ for all $k \geq 0$ [11]. This notion has been used by many authors in the literature, specially on ordered metric spaces and obtaining solutions of some differential equations (see, e.g., [17]).

The condition that the graph is a $C$-graph looks quite strong and in this reason, Aleomraninejad et al. defined the notion of $P$-graphs and showed that these notions are independent on infinite graphs (see [12]). We say that $G$ is a $P$ graph whenever $\left\{x_{n}\right\}_{n \geq 0}$ is a convergent sequence to a point $x$ and $x_{n} \in[x]_{G}$ for all $n \geq 0$, we have $r\left(x_{n}, x\right) \rightarrow 0$ [12]. Here, $r(x, y)$ is the sum of edges distance between $x$ and $y$; that is, $r(x, y)=\sum_{i=1}^{n} d\left(x_{i-1}, x_{i}\right)$. They proved the same results for $C$ graphs and $P$-graphs (see the results of [12]). We will use only $C$-graphs in this paper. 
In this paper, by combining all of these ideas and introducing $G$-type quasi-contractions, we give some results about fixed points of $G$-type quasi-contractions on graphs. The results improve some old results in the literature.

\section{Main Results}

Now, we are ready to state and prove our main results. In 2008, Suzuki obtained the following interesting fixed point result [6].

Theorem 1. Let $(X, d)$ be a complete metric space and let $T$ be a self-map on $X$. Define the nonincreasing function $\theta$ from $[0,1)$ onto $(1 / 2,1]$ by

$$
\theta(r)= \begin{cases}1 & \text { if } 0 \leq r \leq \frac{(\sqrt{5}-1)}{2}, \\ (1-r) r^{-2} & \text { if } \frac{(\sqrt{5}-1)}{2}<r<2^{-1 / 2}, \\ (1+r)^{-1} & \text { if } 2^{-1 / 2} \leq r<1 .\end{cases}
$$

Assume that there exists $r \in[0,1)$, such that

$\theta(r) d(x, T x) \leq d(x, y)$ implies that $d(T x, T y) \leq r d(x, y)$

for all $x, y \in X$. Then, there exists a unique fixed point $z$ of $T$. Moreover, $\lim _{n \rightarrow \infty} T^{n} x=z$ for all $x \in X$.

Throughout this paper, suppose that $E=E(G)$ and $G$ is a C-graph.

Definition 2. Let $(X, d)$ be a metric space, $T$ a self map on $X$, and $G$ a graph with $V(G)=X$. We say that $T$ is a $G$-type quasi-contraction whenever $T$ preserves the edges of $G$ and there exists $r \in[0,1)$, such that

$$
\begin{aligned}
\theta(r) d(x, T x) & \leq d(x, y) \text { implies that } d(T x, T y) \\
& \leq r M(x, y)
\end{aligned}
$$

for all $(x, y) \in E$, where

$$
\begin{aligned}
M(x, y) & \\
=\max & \{d(x, y), d(x, T x), d(y, T y), \\
& \left.\frac{1}{2}[d(x, T y)+d(y, T x)]\right\} .
\end{aligned}
$$

Theorem 3. Let $(X, d)$ be a complete metric space, $T$ a $G$ type quasi-contraction map with $r^{2}+r<1$ such that $(x, T x)$, $\left(x, T^{2} x\right) \in E(G)$ for all $x \in X$. Then, $T$ has a unique fixed point.
Proof. Take $x_{0} \in X$. Since $\theta(r) d\left(x_{0}, T x_{0}\right) \leq d\left(x_{0}, T x_{0}\right)$, we have

$$
\begin{aligned}
& d\left(T x_{0}, T^{2} x_{0}\right) \\
& \quad \leq r \max \left\{d\left(x_{0}, T x_{0}\right), d\left(T x_{0}, T^{2} x_{0}\right), \frac{1}{2} d\left(x_{0}, T^{2} x_{0}\right)\right\} \\
& \quad \leq r \max \left\{d\left(x_{0}, T x_{0}\right), d\left(T x_{0}, T^{2} x_{0}\right)\right\} .
\end{aligned}
$$

Since $(1 / 2) d\left(x_{0}, T^{2} x_{0}\right) \leq(1 / 2)\left[d\left(x_{0}, T x_{0}\right)+d\left(T x_{0}, T^{2} x_{0}\right)\right]$, we obtain $d\left(T^{2} x_{0}, T x_{0}\right) \leq r d\left(x_{0}, T x_{0}\right)$. Hence,

$$
d\left(T^{n} x_{0}, T^{n+1} x_{0}\right) \leq r^{n} d\left(x_{0}, T x_{0}\right)
$$

for all natural number $n$ and so $\left\{T^{n} x_{0}\right\}_{n \geq 1}$ is a Cauchy sequence. Since $X$ is complete, $\left\{T^{n} x_{0}\right\}_{n \geq 1}$ converges to some $x^{*} \in X$. Since $G$ is a $C$-Graph, there is a subsequence $\left\{T^{n_{k}} x_{0}\right\}_{k \geq 1}$ such that $\left(T^{n_{k}} x_{0}, x^{*}\right) \in E$ for all $k \geq 1$. Hence, $\left(T^{n_{k}+j} x_{0}, T^{j} x^{*}\right) \in E$ for all $j \geq 1$. We claim that $T^{j_{0}} x^{*}=x^{*}$ for some natural number $j_{0}$. Arguing by contradiction, we assume that $T^{j} x^{*} \neq x^{*}$ for all $j$. Fix a natural number $j$ and put $x_{n+1}=T^{n} x_{0}$ for all $n \geq 1$. Choose a natural number $n_{0}$ such that $d\left(x_{n}, x^{*}\right) \leq d\left(x^{*}, T^{j} x^{*}\right) / 3$ for all $n \geq n_{0}$. If $n_{k} \geq n_{0}$, then

$$
\begin{aligned}
& d\left(x_{n_{k}+j}, T x_{n_{k}+j}\right) \\
& \quad \leq d\left(x_{n_{k}+j}, x^{*}\right)+d\left(x^{*}, x_{n_{k}+j+1}\right) \\
& \quad \leq \frac{2}{3} d\left(x^{*}, T^{j} x^{*}\right)=d\left(x^{*}, T^{j} x^{*}\right)-\frac{1}{3} d\left(x^{*}, T^{j} x^{*}\right) \\
& \quad \leq d\left(x^{*}, T^{j} x^{*}\right)-d\left(x_{n_{k}+j}, x^{*}\right) \leq d\left(x_{n_{k}+j}, T^{j} x^{*}\right) .
\end{aligned}
$$

It follows that

$$
\begin{aligned}
d\left(T x_{n_{k}+j}, T^{j+1} x^{*}\right) & \\
\leq r \max & \left\{d\left(x_{n_{k}+j}, T^{j} x^{*}\right), d\left(x_{n_{k}+j}, x_{n_{k}+j+1}\right),\right. \\
& d\left(T^{j} x^{*}, T^{j+1} x^{*}\right), \\
& \left.\frac{1}{2}\left[d\left(x_{n_{k}+j}, T^{j+1} x^{*}\right)+d\left(T^{j} x^{*}, x_{n_{k}+j+1}\right)\right]\right\},
\end{aligned}
$$

and $\operatorname{so} d\left(x^{*}, T^{j+1} x^{*}\right) \leq r \max \left\{d\left(x^{*}, T^{j} x^{*}\right), d\left(T^{j} x^{*}, T^{j+1} x^{*}\right)\right\}$. Since $d\left(T^{j} x^{*}, T^{j+1} x^{*}\right) \leq r^{j} d\left(x^{*}, T x^{*}\right)$, we obtain

$$
d\left(x^{*}, T^{j+1} x^{*}\right) \leq r^{j} d\left(x^{*}, T x^{*}\right)
$$

for all $j$. Now, we assume that $d\left(x^{*}, T^{2} x^{*}\right)<d\left(T^{2} x^{*}, T^{3} x^{*}\right)$; then by (6), we have

$$
\begin{aligned}
d\left(x^{*}, T x^{*}\right) & \leq d\left(x^{*}, T^{2} x^{*}\right)+d\left(T x^{*}, T^{2} x^{*}\right) \\
& <d\left(T^{2} x^{*}, T^{3} x^{*}\right)+d\left(T x^{*}, T^{2} x^{*}\right) \\
& \leq r^{2} d\left(x^{*}, T x^{*}\right)+r d\left(x^{*}, T x^{*}\right) .
\end{aligned}
$$


This is a contradiction, since $r^{2}+r<1$. So, we have

$$
d\left(x^{*}, T^{2} x^{*}\right) \geq d\left(T^{2} x^{*}, T^{3} x^{*}\right)=\theta(r) d\left(T^{2} x^{*}, T^{3} x^{*}\right),
$$

and by (3), we obtain

$$
\begin{aligned}
& d\left(T^{3} x^{*}, T x^{*}\right) \\
& \leq r \max \left\{d\left(x^{*}, T^{2} x^{*}\right), d\left(T^{2} x^{*}, T^{3} x^{*}\right), d\left(x^{*}, T x^{*}\right),\right. \\
& \left.\quad \frac{1}{2}\left[d\left(T^{2} x^{*}, T x^{*}\right)+d\left(x^{*}, T^{3} x^{*}\right)\right]\right\} .
\end{aligned}
$$

By considering the above inequality and (9), we deduce that

$$
\begin{aligned}
d\left(x^{*}, T x^{*}\right) & \leq d\left(x^{*}, T^{3} x^{*}\right)+d\left(T x^{*}, T^{3} x^{*}\right) \\
& \leq r^{2} d\left(x^{*}, T x^{*}\right)+r d\left(x^{*}, T x^{*}\right) \\
& \leq\left(r^{2}+r\right) d\left(x^{*}, T x^{*}\right)<d\left(x^{*}, T x^{*}\right),
\end{aligned}
$$

that is a contradiction. Therefore, there exists $j_{0} \in \mathbb{N}$ such that $T^{j_{0}} x^{*}=x^{*}$. Since $\left\{T^{n} x^{*}\right\}_{n \geq 1}$ is a Cauchy sequence, we obtain $x^{*}=T x^{*}$. In fact, if $x^{*} \neq T x^{*}$, from $d\left(T^{n j_{0}} x^{*}, T^{n j_{0}+1} x^{*}\right)=$ $d\left(x^{*}, T x^{*}\right)$ for all $n \geq 1$, it follows that $\left\{T^{n} x^{*}\right\}_{n \geq 1}$ is not a Cauchy sequence. Thus, $x^{*}$ is a fixed point of $T$. The uniqueness of the fixed point follows easily.

Question 1. Does Theorem 3 hold for each $r \in[0,1)$ ?

Theorem 4. Let $(X, d)$ be a complete metric space. Then, the following statements are equivalent

(i) $G$ is weakly connected,

(ii) for each G-type quasi-contraction map $T: X_{T} \rightarrow X_{T}$ and $x, y \in X$, the sequences $\left\{T^{n} x\right\}_{n \geq 1}$ and $\left\{T^{n} y\right\}_{n \geq 1}$ are Cauchy equivalent, where $X_{T}=\{x \in X:(x, T x) \in E\}$,

(iii) for each G-type quasi-contraction map $T: X \rightarrow X$, $\operatorname{card}($ FixT $) \leq 1$.

Proof. (i) $\Rightarrow$ (ii) Let $T: X \rightarrow X$ be a $G$-type quasicontraction map and $x, y \in X$. Since $y \in[x]_{\widetilde{G}}$, there is a path $\left\{x_{0}=x, \ldots, x_{N}=y\right\}$ in $\widetilde{G}$ from $x$ to $y$. Since $\left(x_{i-1}, x_{i}\right) \in$ $E(\widetilde{G}),\left(T^{n} x_{i-1}, T^{n} x_{i}\right) \in E(\widetilde{G})$ for all $n$ and $i=1, \ldots, N$. Let $1 \leq i \leq N$. Put $x_{i-1}=a$ and $x_{i}=b$. If one of the following inequalities holds

$$
\begin{aligned}
& \theta(r) d\left(T^{n-1} a, T^{n} a\right) \\
& \quad \leq d\left(T^{n-1} a, T^{n-1} b\right) \text { or } \theta(r) d\left(T^{n-1} b, T^{n} b\right) \\
& \quad \leq d\left(T^{n-1} b, T^{n-1} a\right) .
\end{aligned}
$$

Then, we have

$$
\begin{aligned}
d\left(T^{n} a, T^{n} b\right) & \\
\leq r \max \{ & d\left(T^{n-1} a, T^{n-1} b\right), d\left(T^{n-1} a, T^{n} a\right), \\
& d\left(T^{n-1} b, T^{n} b\right), \\
& \left.\frac{1}{2}\left[d\left(T^{n-1} a, T^{n} b\right)+d\left(T^{n-1} b, T^{n} a\right)\right]\right\}:=r u_{n} .
\end{aligned}
$$

If $u_{n} \in\left\{d\left(T^{n-1} a, T^{n} a\right), d\left(T^{n-1} b, T^{n} b\right)\right\}$, then

$$
d\left(T^{n} a, T^{n} b\right) \leq r^{n} \max \{d(a, T a), d(b, T b)\} .
$$

$$
\begin{aligned}
& \text { If } u_{n}=(1 / 2)\left[d\left(T^{n-1} a, T^{n} b\right)+d\left(T^{n-1} b, T^{n} a\right)\right] \text {, then } \\
& \qquad \begin{array}{r}
d\left(T^{n} a, T^{n} b\right) \\
\leq r d\left(T^{n-1} a, T^{n} b\right) \text { or } d\left(T^{n} a, T^{n} b\right) \\
\leq r d\left(T^{n-1} b, T^{n} a\right) .
\end{array}
\end{aligned}
$$

Without loss of generality, suppose that $d\left(T^{n} a, T^{n} b\right) \leq$ $r d\left(T^{n-1} a, T^{n} b\right)$. Then,

$$
\begin{aligned}
d\left(T^{n} a, T^{n} b\right) & \leq r d\left(T^{n-1} a, T^{n} b\right) \\
& \leq r d\left(T^{n-1} a, T^{n} a\right)+r d\left(T^{n} a, T^{n} b\right),
\end{aligned}
$$

and so $d\left(T^{n} a, T^{n} b\right) \leq(r /(1-r)) d\left(T^{n-1} a, T^{n} a\right) \leq\left(r^{n} /(1-\right.$ $r) d(a, T a)$. Hence,

$$
d\left(T^{n} a, T^{n} b\right) \leq \frac{r^{n}}{1-r} \max \{d(a, T a), d(b, T b)\} .
$$

Now, suppose that both of the inequalities (14) do not hold. If

$$
\theta(r) d\left(T^{n-1} a, T^{n} a\right)>d\left(T^{n-1} a, T^{n-1} b\right)
$$

then

$$
\begin{aligned}
d\left(T^{n-1} a, T^{n-1} b\right) & <\theta(r) d\left(T^{n-1} a, T^{n} a\right) \\
& \leq \theta(r) r^{n-1} d(a, T a),
\end{aligned}
$$

and so

$$
\begin{aligned}
& d\left(T^{n} a, T^{n} b\right) \\
& \quad \leq d\left(T^{n} a, T^{n-1} a\right)+d\left(T^{n-1} a, T^{n-1} b\right)+d\left(T^{n-1} b, T^{n} b\right) \\
& \quad \leq 3 r^{n-1} \max \{d(a, T a), d(b, T b)\} .
\end{aligned}
$$


If $u_{n}=d\left(T^{n-1} a, T^{n-1} b\right)$, then we can continue in a similar process for $n-1$. In the general case, we get $d\left(T^{n} a, T^{n} b\right) \leq$ $\left(3 r^{n-1} /(1-r)\right) \max \{d(a, T a), d(b, T b)\}$ and so $d\left(T^{n} a, T^{n} b\right) \rightarrow$ 0 . Thus,

$$
\begin{aligned}
d\left(T^{n} x, T^{n} y\right) & \leq \sum_{i=1}^{N} d\left(T^{n} x_{i-1}, T^{n} x_{i}\right) \\
& \leq \frac{3 r^{n-1}}{1-r} \leq \sum_{i=1}^{N} \max \left\{d\left(x_{i-1}, T x_{i-1}\right), d\left(x_{i}, T x_{i}\right)\right\} \\
& \leq 3 N \frac{3 r^{n-1}}{1-r} \max _{1 \leq i \leq N} d\left(x_{i-1}, T x_{i-1}\right) .
\end{aligned}
$$

Therefore, $\left\{T^{n} x\right\}_{n \geq 1}$ and $\left\{T^{n} y\right\}_{n \geq 1}$ are Cauchy equivalent.

(ii) $\Rightarrow$ (iii) Let $x, y \in$ Fix T. By using (ii) and the above process, we obtain easily that $x=y$.

(iii) $\Rightarrow$ (i) If $G$ is not weakly connected, then there exists $x_{0}$ such that $X \backslash\left[x_{0}\right]_{\widetilde{G}}$ is not empty. Take $y_{0} \in X \backslash\left[x_{0}\right]_{\widetilde{G}}$ and define

$$
T x= \begin{cases}x_{0}, & x \in\left[x_{0}\right]_{\widetilde{G}}, \\ y_{0}, & x \in X \backslash\left[x_{0}\right]_{\widetilde{G}} .\end{cases}
$$

Clearly, Fix $T=\left\{x_{0}, y_{0}\right\}$. Now, we show that $T$ is a $G$-type quasi-contraction. For this reason, let $(x, y) \in E$. Since $[x]_{\widetilde{G}}=$ $[y]_{\widetilde{G}}$, either $x, y \in\left[x_{0}\right]_{\widetilde{G}}$ or $x, y \in X \backslash\left[x_{0}\right]_{\widetilde{G}}$. In both cases, we get $T x=T y$. Thus, $T$ is a $G$-type quasi-contraction which has two fixed points. This contradiction completes the proof.

Theorem 5. Let $(X, d)$ be a complete metric space and let $T$ be a $G$-type quasi-contraction and orbitally $G$-continuous selfmap on $X$. Then,

(i) for each $x \in X_{T},\left.T\right|_{[x]_{\widetilde{G}}}$ is a Picard operator,

(ii) $\operatorname{card}(F i x T)=\operatorname{card}\left\{[x]_{\widetilde{G}}: x \in X_{T}\right\}$.

Proof. Let $x \in X_{T}$. Then, $T x \in[x]_{\widetilde{G}}$. It is easy to check that $\left\{T^{n}\right\}_{n \geq 1}$ is a Cauchy sequence. Let $\lim _{n \rightarrow \infty} T^{n} x=x^{*}$. Since $G$ is a $C$-Graph, there exists a subsequence $\left\{T^{n_{k}} x\right\}_{n \geq 1}$ such that $\left(T^{n_{k}} x, x^{*}\right) \in E(G)$ for all $k$. Thus, $\left(T^{n_{k}+1} x, T x^{*}\right) \in E(G)$ for all $k$. Since $\left(T^{n_{k}} x, T^{n_{k}+1} x\right) \in E(G), T x^{*} \in[x]_{\widetilde{G}}$. Since $T$ is orbitally $G$-continuous, $\lim _{n \rightarrow \infty} T^{n_{k}+1} x=x^{*}$ which yields $x^{*}=T x^{*}$. To prove (ii), define the mapping $\pi$ by $\pi(x)=[x]_{\widetilde{G}}$ for all $x \in \operatorname{Fix} T$. It is sufficient to show that $\pi$ is a bijection from Fix $T$ onto $\mathscr{C}=\left\{[x]_{\widetilde{G}}: x \in X_{T}\right\}$. Since $\Delta \subseteq E(G)$, we get Fix $T \subseteq X_{T}$ which yields $\pi(\operatorname{Fix} T) \subseteq \mathscr{C}$. On the other hand, if $x \in X_{T}$, then $\lim _{n \rightarrow \infty} T^{n} x \in[x]_{\widetilde{G}} \bigcap$ Fix $T$ which implies that $\pi\left(\lim _{n \rightarrow \infty} T^{n} x\right)=[x]_{\widetilde{G}}$. Thus, $\pi$ is a surjection from Fix $T$ onto $\mathscr{C}$. Now, if $x_{1}, x_{2} \in \operatorname{Fix} T$ with $\pi\left(x_{1}\right)=\pi\left(x_{2}\right)$, then $x_{2} \in\left[x_{1}\right]_{\widetilde{G}}$ and so by using (i) we obtain

$$
\lim _{n \rightarrow \infty} T^{n} x_{2} \in\left[x_{1}\right]_{\widetilde{G}} \bigcap \text { Fix } T=\left\{x_{1}\right\},
$$

which implies that $x_{2}=x_{1}$. Therefore, $T$ is an injective and this completes the proof.
We need the following results for our last result.

Lemma 6 (see [18]). Let $X$ be a nonempty set and let $T: X \rightarrow$ $X$ be a mapping. Then, there exists a subset $Y \subseteq X$ such that $T Y=T X$ and $T: Y \rightarrow X$ is one-to-one.

Lemma 7 (see [8]). Let $X$ be a nonempty set and that the mappings $f, T: X \rightarrow X$ have a unique point of coincidence $v$ in $X$. If $T$ and $f$ are weakly compatible, then $T$ and $f$ have $a$ unique common fixed point.

Theorem 8. Let $(X, d)$ be a metric space, and let $f$ and $T$ be two self-maps on $X$ such that $T X \subseteq f X$ and $f X$ is complete. Suppose that $f$ and $T$ satisfy the following conditions:

(i) $(f x, f y) \in E(G)$ implies that $(T x, T y) \in E(G)$,

(ii) if $(f x, T x) \in E(G)$ and $T x=f y$ for some $y \in X$, then $(f x, T y) \in E(G)$,

(iii) there exists $r \in[0,1)$ such that $r^{2}+r<1$ and $\theta(r) d(f x, T x) \leq d(f x, f y)$ implies that

$$
\begin{gathered}
d(T x, T y) \\
\leq r \max \{d(f x, f y), d(f x, T x), d(f y, T y), \\
\left.\frac{1}{2}[d(f x, T y)+d(f y, T x)]\right\} .
\end{gathered}
$$

Then, $T$ and $f$ have a unique coincidence point. Moreover, if $T$ and $f$ are weakly compatible, then $T$ and $f$ have a unique fixed point.

Proof. By using Lemma 6, there exists $Y \subset X$ such that $f$ : $Y \rightarrow X$ is one-to-one and $f Y=f X$. Define the self-map $h: f Y \rightarrow f Y$ by $h(f x)=T x$. Clearly, $h$ is well defined and $h$ preserves the edges of $G$. In fact, $(f x, f y) \in E(G)$ implies that $(h f x, h f y) \in E(G)$. Note that $\theta(r) d(f x, h f x) \leq d(f x, f y)$ implies that

$$
\begin{gathered}
d(h f x, h f y) \\
\leq r \max \{d(f x, f y), d(f x, h f x), d(f y, h f y), \\
\left.\frac{1}{2}[d(f x, h f y)+d(f y, h f x)]\right\} .
\end{gathered}
$$

Also, $(f x, h f x)$ and $\left(f x, h^{2} f x\right)$ lie in $E(G)$ for all $x \in Y$. To see this, take $h f x=T x$. Then, $T x=f y$ for some $y \in Y$ and so $h^{2} f x=T y$. By using (ii), $(f x, T y) \in E(G)$. Since $f Y$ is complete, by using Theorem $3, h$ has a unique fixed point in $f Y$, namely, $h f x^{*}=f x^{*}$. Thus, $x^{*}$ is a coincidence point of $f$ and $T$. Note that the assumption (iii) shows the uniqueness of the coincidence point of $f$ and T. Now, by using Lemma 7, it is easy to see that if $f$ and T are weakly compatible, then $f$ and $T$ have a unique fixed point.

\section{Acknowledgment}

The authors would like to thank the anonymous referee for his helpful comments on an earlier version. This article was 
funded by the Deanship of Scientic Research (DSR), King Abdulaziz University, Jeddah. N. Shahzad acknowledges with thanks DSR for financial support.

\section{References}

[1] D. Ilić and V. Rakočević, "Quasi-contraction on a cone metric space," Applied Mathematics Letters, vol. 22, no. 5, pp. 728-731, 2009.

[2] Z. Kadelburg, S. Radenović, and V. Rakočević, "Remarks on "Quasi-contraction on a cone metric space'"' Applied Mathematics Letters, vol. 22, no. 11, pp. 1674-1679, 2009.

[3] Sh. Rezapour, R. H. Haghi, and N. Shahzad, "Some notes on fixed points of quasi-contraction maps," Applied Mathematics Letters, vol. 23, no. 4, pp. 498-502, 2010.

[4] A. Amini-Harandi, "Fixed point theory for set-valued quasicontraction maps in metric spaces," Applied Mathematics Letters, vol. 24, no. 11, pp. 1791-1794, 2011.

[5] R. H. Haghi, Sh. Rezapour, and N. Shahzad, "On fixed points of quasi-contraction type multifunctions," Applied Mathematics Letters, vol. 25, no. 5, pp. 843-846, 2012.

[6] T. Suzuki, "A generalized Banach contraction principle that characterizes metric completeness," Proceedings of the American Mathematical Society, vol. 136, no. 5, pp. 1861-1869, 2008.

[7] S. M. A. Aleomraninejad, Sh. Rezapour, and N. Shahzad, "On fixed point generalizations of Suzuki's method," Applied Mathematics Letters, vol. 24, no. 7, pp. 1037-1040, 2011.

[8] D. Paesano and P. Vetro, "Suzuki's type characterizations of completeness for partial metric spaces and fixed points for partially ordered metric spaces," Topology and Its Applications, vol. 159, no. 3, pp. 911-920, 2012.

[9] F. Echenique, "A short and constructive proof of Tarski's fixedpoint theorem," International Journal of Game Theory, vol. 33, no. 2, pp. 215-218, 2005.

[10] R. Espínola and W. A. Kirk, "Fixed point theorems in $\mathbb{R}$-trees with applications to graph theory," Topology and Its Applications, vol. 153, no. 7, pp. 1046-1055, 2006.

[11] J. Jachymski, "The contraction principle for mappings on a metric space with a graph," Proceedings of the American Mathematical Society, vol. 136, no. 4, pp. 1359-1373, 2008.

[12] S. M. A. Aleomraninejad, Sh. Rezapour, and N. Shahzad, "Some fixed point results on a metric space with a graph," Topology and Its Applications, vol. 159, no. 3, pp. 659-663, 2012.

[13] I. Beg, A. R. Butt, and S. Radojević, "The contraction principle for set valued mappings on a metric space with a graph," Computers \& Mathematics with Applications, vol. 60, no. 5, pp. 1214-1219, 2010.

[14] G. Gwóźdź-Łukawska and J. Jachymski, "IFS on a metric space with a graph structure and extensions of the Kelisky-Rivlin theorem," Journal of Mathematical Analysis and Applications, vol. 356, no. 2, pp. 453-463, 2009.

[15] T. Kamran, M. Samreen, and N. Shahzad, "Probabilistic Gcontractions," Fixed Point Theory and Applications, vol. 2013, article 223, 2013.

[16] M. Samreen, T. Kamran, and N. Shahzad, "Some fixed point theorems in b-metric space endowed with graph," Abstract and Applied Analysis, vol. 2013, Article ID 967132, 9 pages, 2013.

[17] R. P. Agarwal, M. A. El-Gebeily, and D. O’Regan, “Generalized contractions in partially ordered metric spaces," Applicable Analysis, vol. 87, no. 1, pp. 109-116, 2008.
[18] R. H. Haghi, Sh. Rezapour, and N. Shahzad, "Some fixed point generalizations are not real generalizations," Nonlinear Analysis $A$, vol. 74, no. 5, pp. 1799-1803, 2011. 


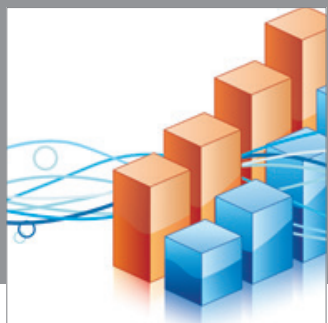

Advances in

Operations Research

mansans

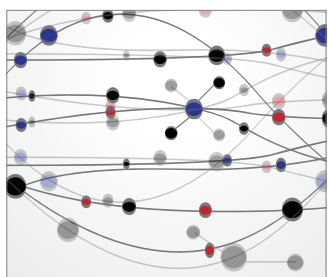

The Scientific World Journal
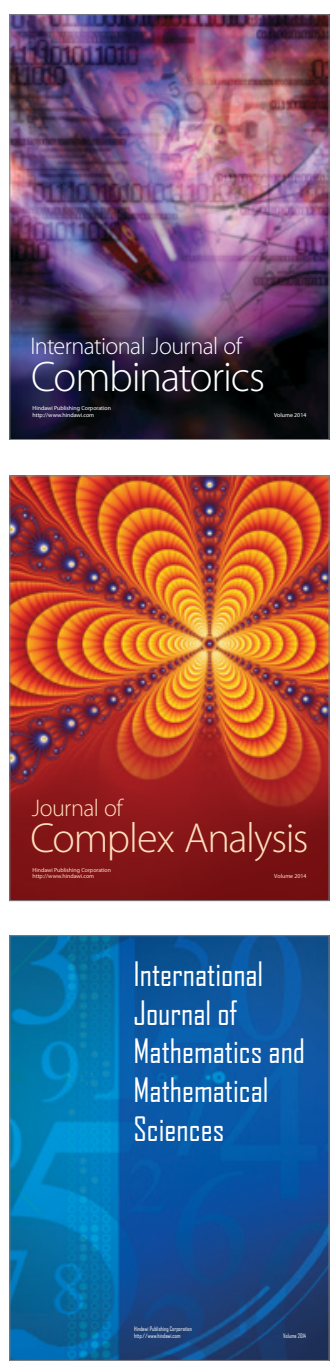
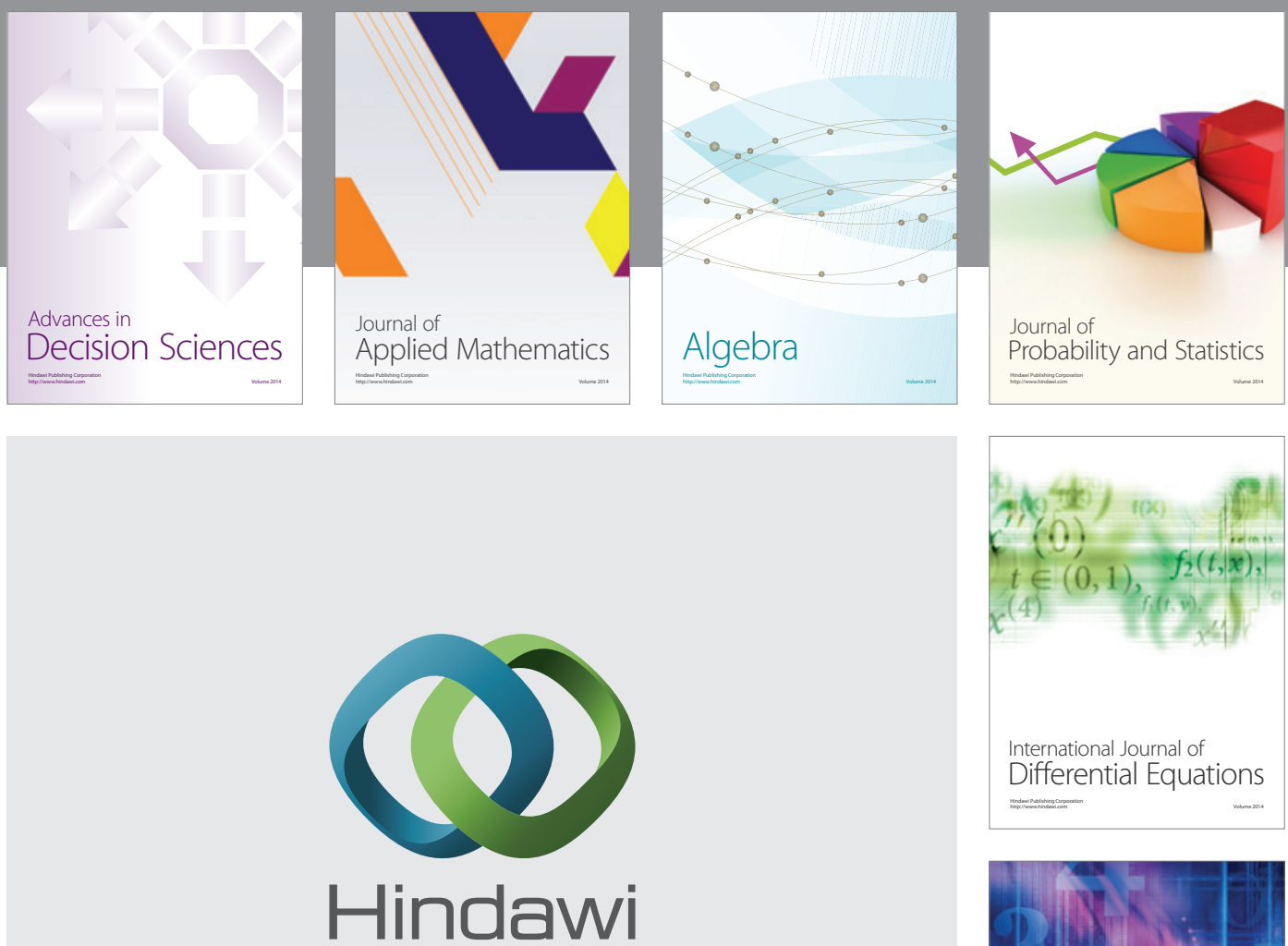

Submit your manuscripts at http://www.hindawi.com
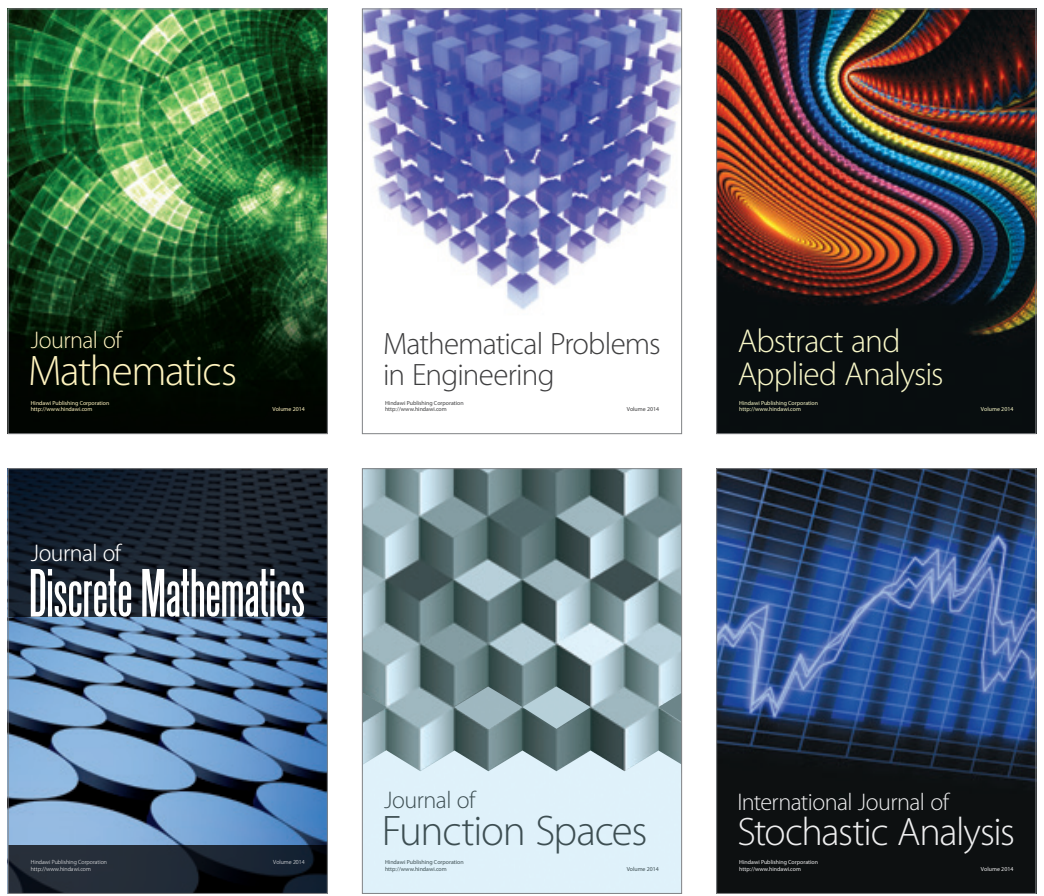

Journal of

Function Spaces

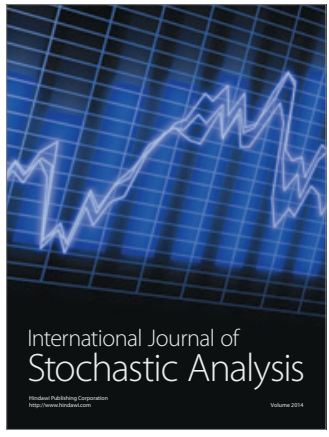

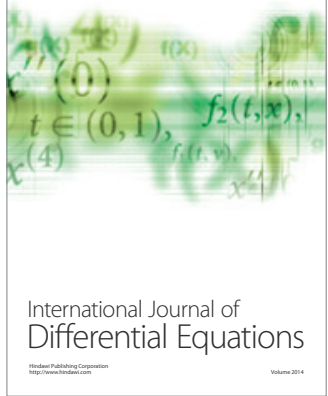
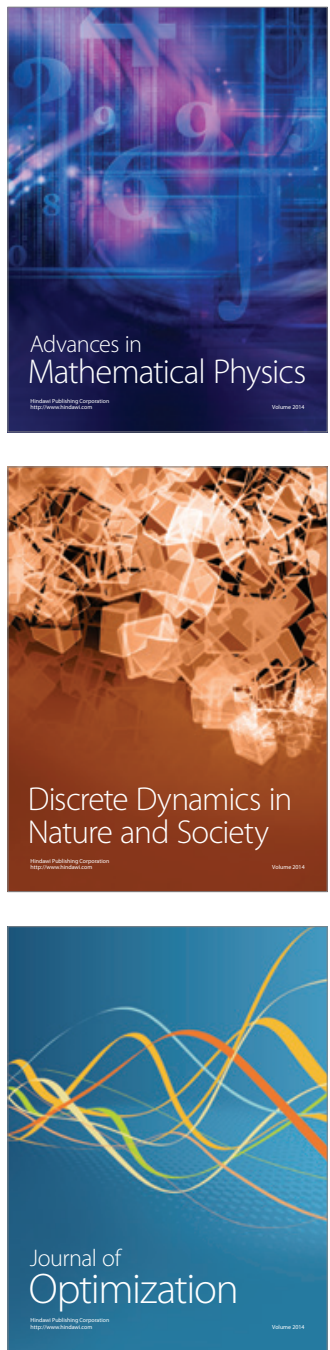